\title{
BRINCANDO COM OS RESÍDUOS: REUTILIZAÇÃO E RECICLAGEM NA EDUCAÇÃO INFANTIL
}

\author{
Mariana Guenther ${ }^{1}$ \\ Mario Leandro dos Santos Ferreira ${ }^{2}$ \\ Alef Diogo da Silva Santana ${ }^{3}$
}

Resumo: $O$ presente estudo teve como objetivo desenvolver e aplicar atividades lúdicas utilizando como temática a redução, a reutilização e a reciclagem dos resíduos com crianças de 02 a 04 anos da Creche Municipal Professor Francisco Amaral, localizada no bairro de Santo Amaro, Recife com o fim de desenvolver uma consciência crítica sobre a destinação e tratamento adequados dos resíduos. Tais atividades incluíram rodas de conversas, oficinas de construção de brinquedos a partir de resíduos domésticos, apresentação de teatro e exibição de vídeo educativo. As crianças participaram ativamente de todas as atividades propostas e apreenderam de forma surpreendente o conteúdo trabalhado. Esperamos que essa experiência inspire ações futuras em outras creches e escolas.

Palavras-chave: Educação Infantil; Atividades Lúdicas; Reciclagem; Reutilização; Resíduos Sólidos. 


\section{Introdução}

Desde o início da civilização, as populações humanas mantiveram uma relação de exploração com os recursos naturais, hoje em franca expansão justificada pela busca de melhores condições de bem-estar, segurança e conforto. A retomada da relação harmônica homem-natureza exige, portanto, mudanças comportamentais profundas para o estabelecimento de uma relação ecologicamente equilibrada, economicamente viável e socialmente justa.

A educação ambiental como meio de sensibilização, conscientização, mudança de hábitos, e desenvolvimento da cidadania é peça chave na construção de uma sociedade consciente e igualitária. De natureza multi e transdisciplinar, englobando várias áreas como a biologia, a ecologia, a economia, a sociologia, a comunicação social e a política, e diversos segmentos da sociedade, a educação ambiental é amplamente democrática, atingindo todas as faixas etárias, classes sociais, culturas, credos e religiões (REIGOTA, 2010). É, portanto uma das ferramentas fundamentais para adequar o homem a seu espaço por meio de incentivos à análise crítica de sua realidade, usando a observação e sensibilização do indivíduo e gerando nele a sensação de pertencimento.

Com o auxílio de um conhecimento teórico prévio, torna-se possível a criação e aplicação de práticas sustentáveis efetivas, estimuladas através de conversas, questionários e instrumentação lúdica. Há diferentes juízos de valores formados e absorvidos durante e após uma abordagem em Educação Ambiental, dependentes, sobretudo, da percepção ambiental de cada indivíduo, ou seja, do grau de interação e entendimento das responsabilidades deste com seu entorno. Neste cenário, a educação ambiental é construída por duas linhas de ação que se complementam e são interdependentes: a linha ativa e a reflexiva. A ação deve ser o resultado da reflexão, e a reflexão sem ação não tem resultado (REIGOTA, 2010). Assim, seu objetivo principal consiste na conscientização da sociedade sobre do funcionamento do meio ambiente e seus modos de preservação e utilização racional e sustentável, buscando mudar radicalmente as relações atuais entre o homem e as demais espécies viventes, recriando o círculo virtuoso que o mantém inserido no seu meio (PINOTTI, 2010).

A educação infantil no Brasil, apesar dos inestimáveis avanços preconizados por grandes educadores e filósofos da educação como Jean Piaget (1896-1980) e Paulo Freire (1921-1997), ainda está muito focada em métodos tradicionais de desenvolvimento psicomotor criando poucos espaços para a criação, conscientização e formação de capacidade crítica nas crianças em sua primeira infância (FREIRE, 2009). Estudos recentes vêm demonstrando a capacidade de raciocínio lógico e, portanto, o desenvolvimento de análise crítica em crianças desde a mais tenra idade (e.g. GOPNIK et al., 1999; HIRSH-PASEK; GOLINKOFF, 2003), abrindo espaço para a criação de novos métodos de aproveitamento e desenvolvimento de sua capacidade cognitiva. 
A escola é um espaço importante de socialização e troca de experiências, e quanto mais cedo no desenvolvimento infantil a Educação Ambiental for aplicada, maiores as chances de se alcançar uma consciência ambiental efetiva. A educação ambiental no ensino formal vem atuando principalmente no âmbito do ensino fundamental e médio, ainda baseando-se na ideia de que esta faixa etária esteja mais apta a receber e compreender as informações passadas. Acreditamos, no entanto, que a educação ambiental focada na primeira infância permite criar desde cedo um pensamento crítico relacionado ao modo como lidamos com o meio ambiente. Em longo prazo, serão gerados indivíduos que se entendem como parte do ambiente e uma sociedade atenta aos problemas ambientais, procurando medidas viáveis e eficazes para solucioná-los.

O objetivo do presente estudo foi desenvolver e aplicar atividades lúdicas utilizando como temática a redução, reutilização e reciclagem dos resíduos com crianças de 02 a 04 anos com o fim de desenvolver uma consciência crítica sobre a destinação e tratamento corretos dos resíduos. Essas atividades fazem parte do Projeto de Extensão "Educação ambiental no ensino infantil: sensibilizando a primeira infância" da Universidade de Pernambuco.

\section{Metodologia}

Esse estudo foi desenvolvido na Creche Municipal Professor Francisco Amaral, localizada no bairro de Santo Amaro, Recife - PE (Figura 1) com duas turmas de 20 alunos cada, a primeira de 2-3 anos (turma A) e a segunda de 3-4 anos (turma B). A metodologia adotada neste estudo atende, rigorosamente, aos preceitos éticos e legais exigidos para a pesquisa científica em Ciências Humanas sendo aprovada no Comitê de Ética em Pesquisa de nossa Instituição.

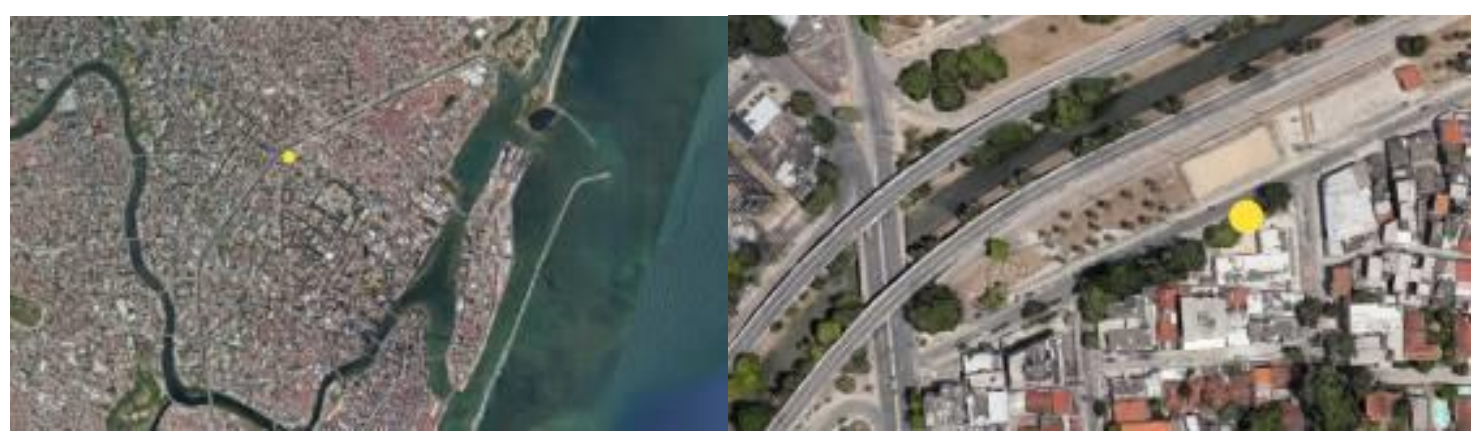

Figura. 1: Localização da área de estudo. À esquerda vista aérea da cidade do Recife com destaque para o Rio Capibaribe desaguando no Oceano Atlântico - área de estudo em amarelo. À direita detalhe do canal da Av. Agamenon Magalhaes localizado em frente à área de estudo (em amarelo). Fonte: Google Maps. 
Para a turma $A$ foram realizados três encontros distantes em uma semana cada. No primeiro encontro realizamos uma roda de conversa com o objetivo de se avaliar o conhecimento prévio das crianças sobre a gestão dos resíduos: o que são, como descartá-los corretamente, quais seriam as consequências do seu descarte incorreto, como por exemplo, nas ruas, etc. Neste mesmo encontro confeccionamos, com a ajuda das crianças, bonecos fantoches com jornal e rolos de papel higiênico, trazidos previamente pelas crianças.

No segundo encontro, encenamos uma peça de teatro com os fantoches confeccionados no encontro anterior sobre os problemas causados pela destinação incorreta dos resíduos.

No terceiro e último encontro utilizamos material reciclado trazido pelas crianças (solicitados previamente) como garrafas PET, embalagens Tetra Pak de sucos e leites e caixas de papelão para a confecção de brinquedos (carrinhos, aviões, bonecos) a partir desse material.

Para a turma B foram realizadas três atividades em um mesmo encontro. A primeira consistiu em uma roda de conversa com o objetivo de se avaliar o conhecimento prévio das crianças sobre a gestão dos resíduos, assim como na turma $A$. Em seguida realizamos a confecção de bonecos a partir de jornal e rolos de papel higiênico como na turma $A$, sendo que nesta turma as crianças tiveram maior autonomia para confeccionar seus bonecos. Por fim, assistimos a um vídeo sobre a importância da redução da geração de resíduos, sua reutilização e reciclagem, seguido de uma nova roda de conversas.

\section{Resultados e Discussão}

\section{Turma A (2-3 anos)}

\section{Conhecimento prévio}

As crianças da turma $A$ demonstraram claro conhecimento sobre os problemas resultantes do descarte incorreto dos resíduos. Mencionaram claramente a proliferação de ratos e baratas que trazem doenças, bem como 0 aspecto estético, de como "a cidade fica feia com tanto lixo no chão". Alguns mencionaram também o problema dos rios e mares que recebem esses resíduos carreados pelas chuvas, "matando os peixes". Assim, além do problema estético e de saúde, as crianças também demonstraram consciência sobre os danos ambientais decorrentes do descarte indevido dos resíduos nas vias públicas.

A escola onde foi desenvolvido esse estudo está localizada em uma grande avenida que margeia um braço do principal rio da cidade, o Rio Capibaribe, que desemboca no mar em alguns quilômetros dali (ver Figura 1). Essa porção do rio encontra-se bastante poluída, exalando fortes odores e carreando uma grande quantidade de resíduos. Dessa forma, o convívio diário das crianças com essa situação permite um entendimento claro sobre os danos causados pela poluição.

Revbea, São Paulo, V. 14, No 1: 101-110, 2019. 
Perguntados sobre onde eles descartam os resíduos, todos mencionaram o lixeiro, seja em casa ou na escola. Ficamos muito bem impressionados com a consciência das crianças em relação ao tratamento dos resíduos e os problemas relacionados ao seu descarte incorreto. Apesar, ou talvez pelo fato, de viverem em uma área bastante descuidada em termos de saneamento, essas crianças já têm uma visão bastante clara da importância da limpeza das ruas para o seu bem-estar. A escola onde trabalhamos é extremamente limpa e organizada, e sempre ao final de cada atividade, todas as crianças nos auxiliaram na limpeza e organização do espaço.

Não foram mencionados pelas crianças, no entanto, outros possíveis destinos para os resíduos, como a reutilização ou reciclagem, o que nos estimulou e direcionou às atividades seguintes.

\section{1a Oficina}

A primeira oficina realizada com a turma $A$ ocorreu no primeiro encontro, logo após a roda de conversa. A partir de rolos de papel higiênico trazidos pelas próprias crianças, jornal e material de pintura e colagem fornecido pela escola, ensinamos às crianças como confeccionar um boneco fantoche (Figura 2).

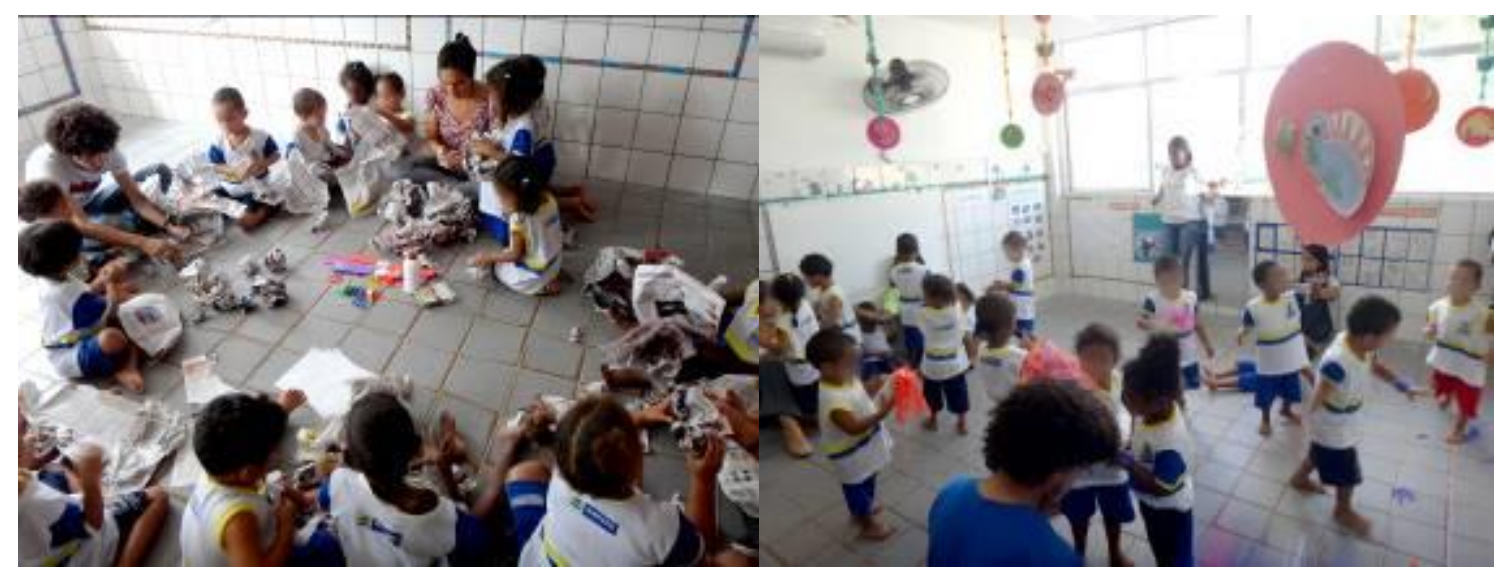

Figura 2: Confecção de bonecos fantoches a partir de rolo de papel higiênico e jornal: turma A.

Fonte: os autores.

Durante o processo de confecção conversamos sobre a importância de reutilizar os resíduos ao invés de descartá-los, trazendo a ideia da redução do volume descartado (quanto menos resíduos, melhor) e da economia que há por trás desse processo (não precisando comprar o material). Assim, discutimos a importância econômica e ambiental da reutilização dos resíduos sólidos em uma linguagem simples e lúdica.

A participação das crianças na oficina foi surpreendente. Todos os 20 alunos observavam atentos ao passo-a-passo da confecção dos bonecos, participando ativamente da conversa e auxiliando sua produção. Ao final desta

revista brasileira educação ambiental 
primeira oficina todos puderam brincar com os bonecos que foram então guardados para a próxima atividade.

Solicitamos aos alunos que juntassem todo o material que tivessem em casa (caixas de leite, suco, embalagens plásticas, garrafas PET, caixas de papelão) para trazer no nosso $3^{\circ}$ encontro em duas semanas. E solicitamos também às professoras e à diretora que reforçassem a solicitação junto aos pais ou responsáveis.

\section{Apresentação teatral}

No segundo encontro com a turma $A$, montamos um pequeno palco juntando duas mesas e uma toalha de TNT em torno do qual as crianças se acomodaram. Os personagens da peça foram os bonecos fantoches construídos por eles no encontro anterior (Figura 3).

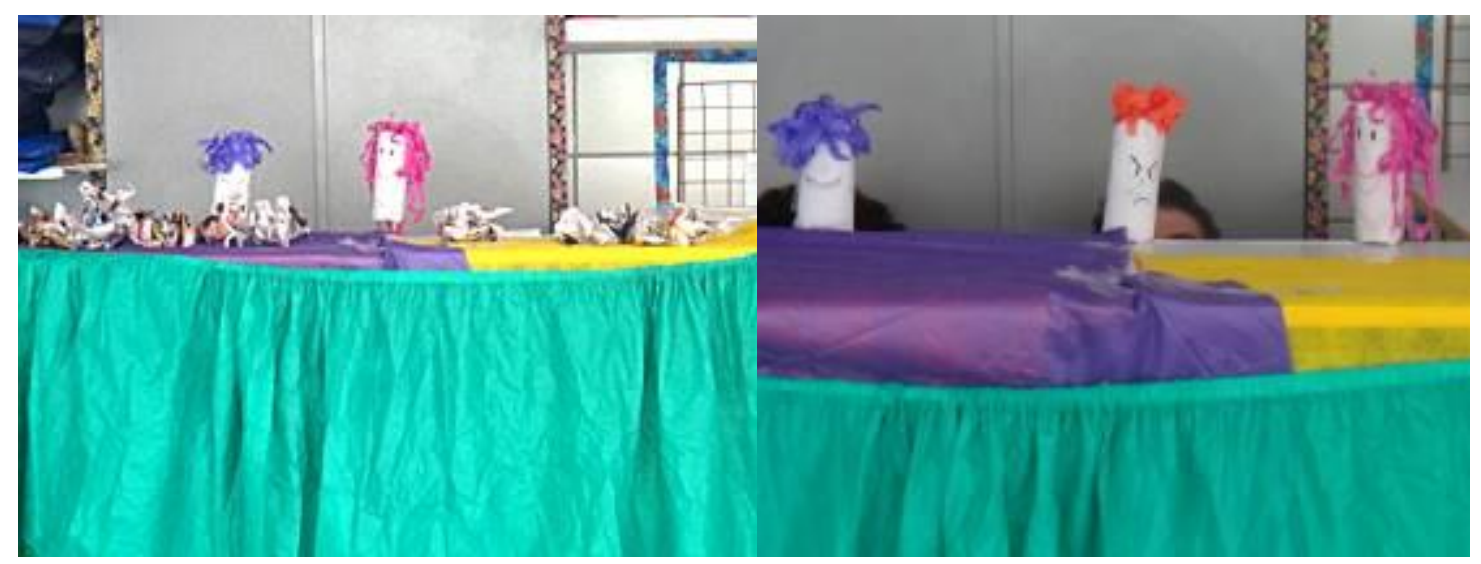

Figura 3: Apresentação teatral para a turma A com os bonecos fantoches produzidos.

Fonte: os autores.

As crianças se surpreenderam e demonstraram grande excitação ao reconhecerem seus trabalhos no teatro. Com um enredo direto e diálogos simples, buscamos discutir de forma divertida o problema do descarte indevido dos resíduos nas vias públicas. Dois rapazes e uma moça compunham a trama, onde um não se preocupava com o ambiente e descartava os resíduos no chão, e os demais tentavam convencê-lo de que além de matar os animais e as plantas e destruir os rios e os mares, ele mesmo sofreria as consequências dos seus atos. No final ele percebe que ele mesmo estava adoecendo com tantos resíduos em volta e resolve que a partir de então, mudará de atitude.

As crianças participaram atentas de todo o espetáculo, que durou aproximadamente 15 minutos, respondendo ativamente aos diálogos e às perguntas dos personagens. Foi um momento de extrema diversão. Podemos perceber já a apreensão de alguns conceitos trabalhados anteriormente na primeira oficina, como a reutilização dos resíduos que estariam sendo jogados na rua para a construção de outros materiais (como os bonecos, por exemplo!). 
2aㅡㅁina

A segunda oficina realizada com a turma A ocorreu no terceiro encontro, a partir do material trazido pelas crianças e material de pintura e colagem fornecido pela escola. Neste momento as crianças estiveram livres para escolher seu material e pensar junto conosco em ideias do que construir a partir deste.

Antes de iniciarmos a atividade, perguntamos quais seriam seus brinquedos preferidos, ao que todos listaram os brinquedos mais famosos das lojas e propagandas de TV. Então perguntamos: $E$ se nós mesmos construíssemos nossos próprios brinquedos, sem gastar dinheiro, com tudo o que temos em casa?

Aos olhares curiosos e desconfiados com essa pergunta, seguiu-se um alvoroço de mãozinhas ávidas por escolher o seu material e construir seu brinquedo favorito. Carrinhos, trens, aviões, chapéus, espadas, robôs e bonecas, foram alguns dos brinquedos produzidos com muita alegria e capricho. Tivemos receio de uma possível frustação quando da comparação entre os brinquedos ali produzidos e aqueles das lojas e propagandas de TV. Mas a alegria da criação foi tamanha que estes se transformaram nos brinquedos mais valiosos do mundo!

Essa última atividade teve como objetivo avaliar todo o processo de educação ambiental desenvolvido com esse grupo, incluindo a roda de conversa, a primeira oficina e a apresentação teatral. Muitos já estavam planejando, ao longo do processo de construção dos brinquedos, o que mais poderiam fazer a partir de quais resíduos. Já combinavam com os colegas o que iriam juntar, a quem mais pedir - tios, amigos e vizinhos - caixas, garrafas e papéis, para produzir mais brinquedos para todas as crianças da escola, da rua, do bairro. Foi extremamente gratificante perceber que atividades tão simples puderam surtir tanto efeito no pensamento e atitudes destas crianças. De fato, foi evidente a evolução dessas crianças ao longo dessas três semanas no sentido da apropriação do conhecimento construído e da aplicação desse novo conhecimento em suas atitudes.

\section{Turma B (3-4 anos)}

\section{Conhecimento prévio}

A turma $B$ se mostrou de um modo geral, mais agitada que a turma $A$. No entanto, a roda de conversa fluiu bem. Quando perguntados sobre os problemas que o descarte indevido dos resíduos nas vias públicas poderia causar, as crianças demonstraram conhecimento tanto sobre os aspectos estéticos ("lixo na rua é feio, tem cheiro ruim!") e de saúde ("junta muito rato e barata que traz doenças pra gente!") quanto sobre o impacto ambiental que os resíduos podem causar quando "são levados pela chuva até o rio e o mar, matando os animais e as plantas". 
Como mencionado anteriormente, a realidade da região onde as crianças moram e transitam todos os dias, com resíduos espalhados pelas ruas e flutuando no rio e odores fortes constantes por onde passam, ao invés de torná-los acostumados a essa situação, permite uma maior sensibilização e conscientização, conforme podemos perceber quando perguntamos sobre 0 destino que davam aos resíduos em casa e na escola. A turma foi unanime em anunciar que jogavam na lixeira, como podemos constatar pela organização e limpeza da escola e pela atitude deles ao fim de cada atividade.

Como na turma anterior, também não foram mencionadas práticas como a reutilização ou reciclagem como um destino alternativo aos resíduos depositados nas lixeiras. Nenhuma criança mencionou a separação dos resíduos em casa, por exemplo. Assim, passamos para nossa próxima atividade com foco na reutilização dos resíduos domésticos.

\section{Oficina}

A oficina realizada com a turma $B$ ocorreu logo após a roda de conversa. Ao final da discussão sobre o problema estético, de saúde e ambiental causado pelo descarte incorreto dos resíduos propomos: Por que não reutilizar parte desses resíduos? Assim, seguindo o mesmo procedimento realizado com a turma $A$, confeccionamos bonecos fantoches a partir de rolos de papel higiênico trazidos pelas próprias crianças, jornal e material de pintura e colagem fornecido pela escola. Nessa turma, porém, cada um confeccionou seu próprio boneco, sendo apenas auxiliados por nós (Figura 4).

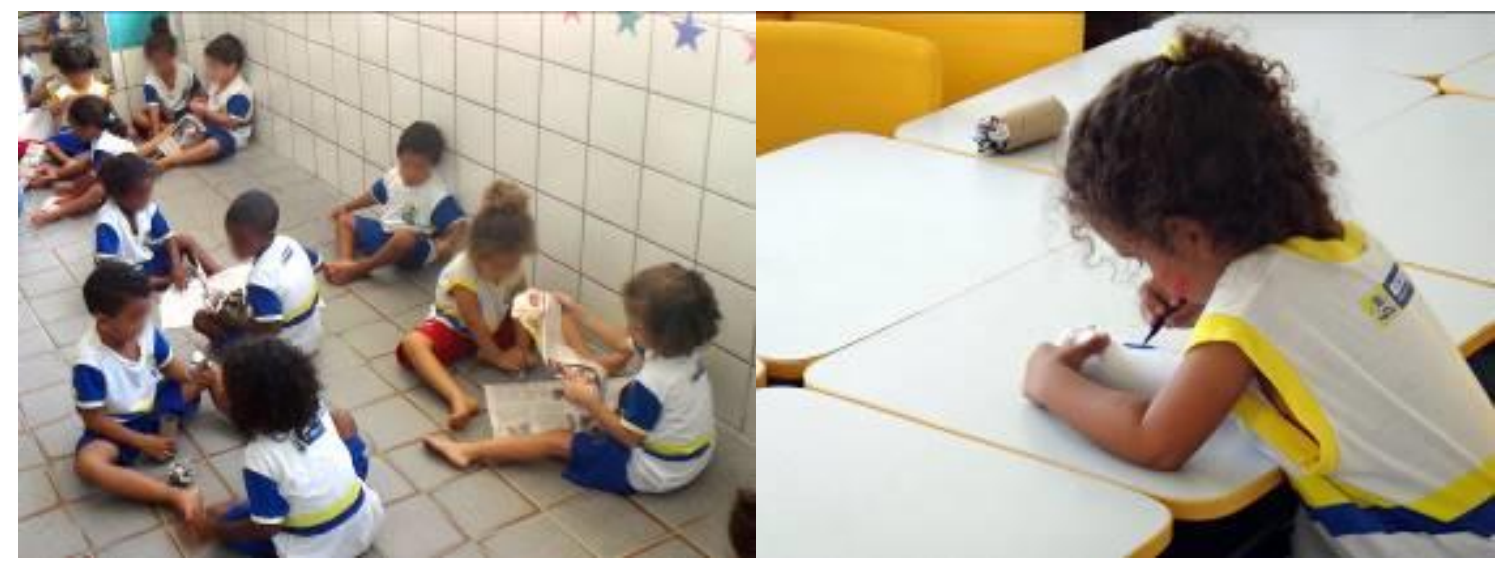

Figura 4: Confecção de bonecos fantoches a partir de rolo de papel higiênico e jornal: turma B.

Fonte: os autores.

Tal qual na primeira oficina desenvolvida com a turma $A$, discutimos a importância da reutilização dos resíduos que nós mesmos produzimos, seja para diminuir a quantidade de resíduos nas lixeiras e nas ruas, seja para diminuir os gastos com materiais novos. A receptividade das crianças à atividade foi excelente. Apesar da agitação inicial, quando foram distribuídos os materiais para confecção dos bonecos todos se sentaram e se concentraram na atividade. Com muita atenção e cuidado, cada um foi produzindo seus 
bonecos e ao final todos se juntaram para brincar com seus brinquedos novos. Foi um momento de grande alegria e descontração.

Durante a oficina foi possível perceber o encantamento das crianças em produzir seu próprio brinquedo, ao ver que de rolos de papel higiênico e jornais, alguns lápis, cola e um novelo de lã seria possível surgir tanta brincadeira e diversão. Através dessa simples atividade, trabalhamos não só a reutilização de resíduos, mas a autoestima das crianças ao se verem capazes de produzir algo, e a redução do consumismo, ao verem que é possível se divertir com tão pouco.

\section{Vídeo}

Após as oficinas, as crianças tiveram um intervalo para o lanche e depois vieram para a sala de vídeo que já estava toda preparada com colchonetes para recebê-los. Escolhemos um vídeo da Turma da Monica intitulado: Um plano para salvar o planeta, da turma da Monica (São Paulo: Maurício de Souza Produções, 2011, 25min, son., color) onde é apresentada a solução dos $3 R$ s (reduzir, reutilizar e reciclar) para o problema do acúmulo de resíduos no planeta. Esse vídeo foi escolhido por apresentar um enredo rico em termos de conteúdo e uma linguagem apropriada para a faixa etária, além de conter personagens conhecidos das crianças. As crianças assistiram atentamente aos 10 minutos de vídeo e depois conversamos um pouco sobre as impressões deles em relação à estória (Figura 5). Decidimos passar o vídeo para essa turma ao invés da apresentação teatral realizada na turma $A$, porque pensamos que prenderia mais a atenção da turma, que se mostrava mais agitada e dispersa do que a anterior. De fato, foi uma decisão bastante acertada.

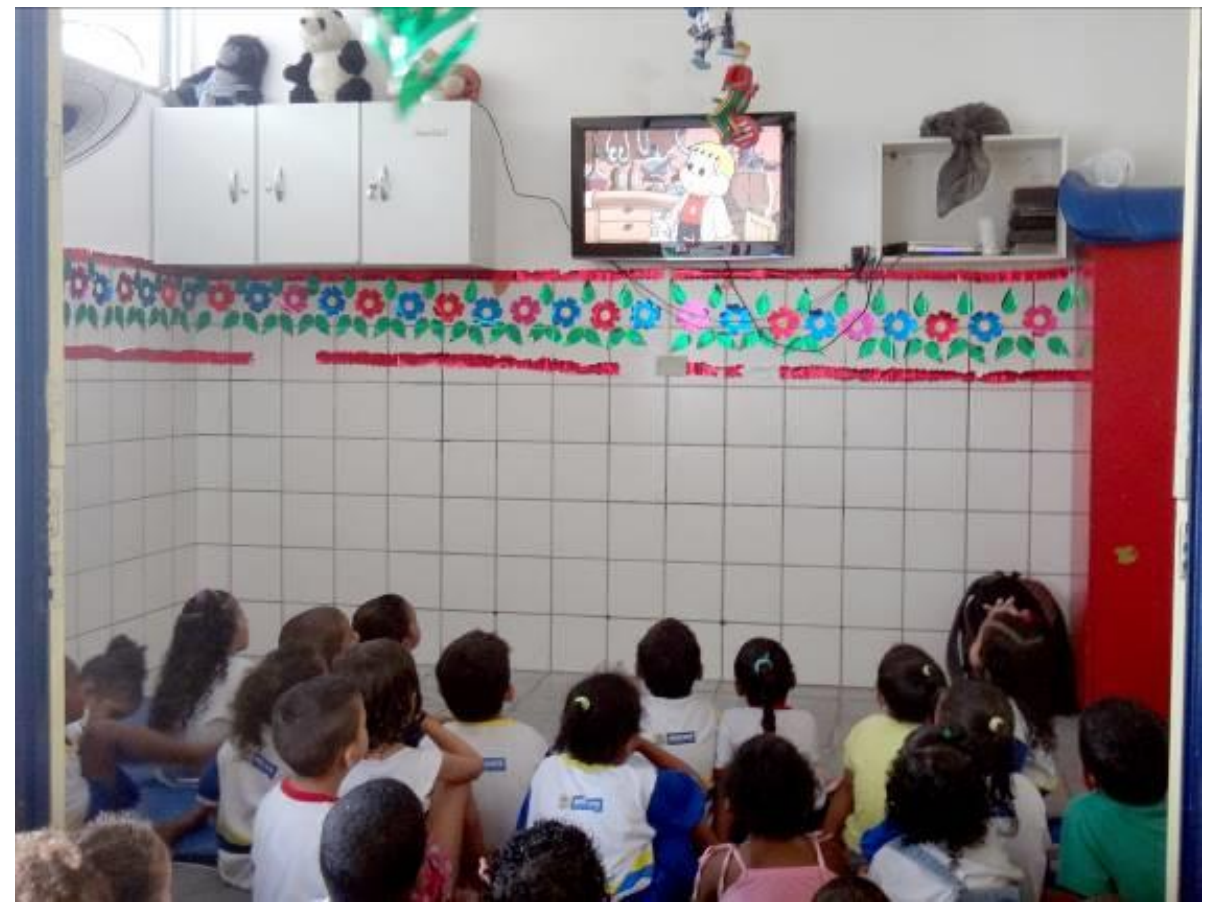

Figura 5: Exibição de vídeo educativo para a turma B. Fonte: os autores 


\section{$\underline{\text { Roda de conversa - avaliação }}$}

A roda de conversa após a apresentação do vídeo teve como objetivo avaliar o que eles apreenderam de toda a dinâmica, incluindo a primeira roda de conversa, a oficina e o vídeo. Reutilização e reciclagem foram termos presentes em todas as falas, e apesar de alguma dificuldade em diferenciar os dois termos, foi possível verificar que muito possivelmente a reutilização de materiais em casa e a separação dos resíduos sólidos para reciclagem passariam a ser um hábito na vida daquelas crianças. Em apenas um dia de atividades, a apreensão dos conceitos trabalhados foi bastante evidente.

\section{Conclusões}

Ao fim da execução desse projeto de Educação Ambiental com as duas turmas da Creche Municipal Professor Francisco Amaral, concluímos que as atividades realizadas (rodas de conversa, oficina de criação de brinquedos, teatro de fantoches e exibição de vídeo) se mostraram plenamente adequadas para a faixa etária e satisfatórias quanto ao objetivo do projeto. As crianças se mostraram interessadas e participativas em todas as atividades e apreenderam de forma surpreendente 0 conteúdo trabalhado. $O$ conceito de reaproveitamento dos resíduos para a confecção de outros objetos foi incorporado por todos. E a semente da separação dos resíduos para a reciclagem foi plantada. Foi uma grande satisfação realizar esse projeto e esperamos que sirva de inspiração para ações futuras em outras creches e escolas.

\section{Agradecimentos}

Agradecemos imensamente à Direção da Creche Municipal Professor Francisco Amaral por nos ter recebido de braços abertos, às professoras das turmas do Maternal que nos auxiliaram nas atividades, aos pais e responsáveis pelos alunos que permitiram sua participação nas atividades e que contribuíram com o envio de materiais para serem trabalhados em sala de aula e, principalmente, aos pequeninos alunos, razão de todo nosso esforço e satisfação. Esse projeto contou com o apoio financeiro da Universidade de Pernambuco através do edital PROEC/PFAUPE/UPE № 01/2014.

\section{Referências}

FREIRE, P. Pedagogia da autonomia: saberes necessários à prática educativa. São Paulo: Paz e Terra, 2009.

GOPNIK, A., MELTZOFF, A.N. \& KUHL, P.K. The scientist in the crib: what early learning tells us about the mind. New York: HarperCollins Pub. Inc., 1999.

HIRSH-PASEK, K.; GOLINKOFF, R.M. Einstein never used flash cards: how our children really learn - and why they need to play more and memorize less. Washington: Library of Congress, 2003.

PINOTTI, R. Educação Ambiental para o Século XXI. São Paulo: Editora Blucher, 2010.

REIGOTA, M. O que é Educação Ambiental? São Paulo: Editora Brasiliense, 2010.

Revbea, São Paulo, V. 14, № 1: 101-110, 2019. 